\title{
Ion channels: new tools to track cyclic nucleotide changes in living cells
}

\section{Aniella Abi-Gerges and Rodolphe Fischmeister.}

\author{
Affiliations \\ Aniella Abi-Gerges \\ Univ Pierre et Marie Curie \\ INSERM UMR-S-956 \\ Paris \\ France
}

Rodolphe Fischmeister

INSERM UMR-S-769, LabEx LERMIT

Univ Paris-Sud, Faculty of Pharmacy

Châtenay-Malabry

France

Correspondence to:

Rodolphe FISCHMEISTER

INSERM UMR-S-769

Faculté de Pharmacie

5, Rue J.-B. Clément

F-92296 Châtenay-Malabry Cedex

France

Tel. +33-1-46 835771

Fax +33-1-46 835475

E-mail: rodolphe.fischmeister@inserm.fr 


\section{Synonyms}

Use of ion channels as biosensors; spatiotemporal organization of cyclic nucleotides

\section{Definition}

Ion channels are used as biosensors in order to visualize the spatiotemporal changes that occur in cyclic nucleotides in living cells.

\section{1- Introduction}

Ion channels are pore-forming proteins that allow the flow of ions down their electrochemical gradient thus helping to establish and control the small voltage gradient across the plasma membrane of cells. They are present in the membranes that surround all biological cells and can be distinguished based upon their ion selectivity, gating mechanism, and sequence similarity. Ion channels can be voltage-gated, ligand-gated, pH-gated, or mechanically gated. These gating criteria along with a combination of sequence similarity and ion selectivity further subdivide ion channels into several subtypes:

- Voltage-gated ion channels which open and close in response to membrane potential such as the voltage-gated sodium channels, voltage-gated calcium channels, and some transient receptor potential channels, normally referred to simply as TRP channels.

- Ligand-gated ion channels, also known as ionotropic receptors, open in response to specific ligand molecules binding to the extracellular domain of the receptor protein. Examples of such channels include the cation-permeable "nicotinic" Acetylcholine receptor, ionotropic glutamate-gated receptors and ATP-gated $\mathrm{P} 2 \mathrm{X}$ receptors, and the anion-permeable $\gamma$-aminobutyric acid-gated $\mathrm{GABA}_{\mathrm{A}}$ receptor.

- Other gating includes the light-gated, the temperature-gated, mechanosensitive ion channels and the cyclic nucleotide-gated channels. This latter superfamily of channels 
contains two families that are going to be the topic of this review: the cyclic nucleotide-gated channel (CNG) channels and the hyperpolarization-activated, cyclic nucleotide-gated (HCN) channels.

The study of ion channels involves many scientific techniques such as voltage clamp electrophysiology (in particular patch clamp), immunohistochemistry, and RT-PCR.

\section{2- State of the art}

Cyclic adenosine 3',5'-monophosphate (cAMP) and cyclic guanosine 3',5'monophosphate (cGMP) are ubiquitous second messengers regulating a myriad of cellular functions. In the heart, the force of contraction (inotropy) and beating frequency (chronotropy) are under the dual control of the sympathetic and parasympathetic systems. Both systems control in an opposite manner the synthesis of cAMP, and, hence, the activity of the cAMP effectors (Fig. 1). Catecholamines released into the synaptic cleft at sympathetic nerve terminals bind to $\beta_{1}$-adrenergic receptors $\left(\beta_{1}\right.$-ARs) on the cardiac sarcolemma, activate stimulatory $\mathrm{G}$ proteins $\left(\mathrm{G}_{\mathrm{s}}\right)$, which in turn activate two isoforms of adenylyl cyclase (AC), AC5 and AC6, which catalyze the conversion of ATP to cAMP. cAMP exerts its effects then by activating the cAMP-dependent protein kinase (PKA), thereby promoting the phosphorylation and activation of key components of the excitation-contraction coupling (CEC) process. These include the sarcolemmal L-type $\mathrm{Ca}^{2+}$ channels (LTCC), responsible for the initial $\mathrm{Ca}^{2+}$ influx, the ryanodine receptors, that allow $\mathrm{Ca}^{2+}$ release from the sarcoplasmic reticulum (SR), troponin I, which controls myofilament sensitivity to $\mathrm{Ca}^{2+}$, and phospholamban, which regulates $\mathrm{Ca}^{2+}$ withdrawal from the cytosol and re-uptake into the SR (Bers, 2002). cAMP can also act in cardiac myocytes in a PKA-independent manner, through direct activation of Epac (Morel et al., 2005), a guanine 
nucleotide exchange factor for the small GTPase Rap1 (Bos, 2003), and HCN cyclic nucleotidegated ion channels (Baruscotti et al., 2005). As a mirror image, acetylcholine released into the synaptic cleft at parasympathetic nerve terminals binds to the muscarinic M2 receptors and induces AC inhibition via inhibitory $G$ protein $\left(G_{i}\right)$, thus decreasing PKA activation (Fig. 1) (Dhein et al., 2001).

It is generally accepted that cGMP opposes the effect of cAMP on cardiac function (Fischmeister et al., 2005). Intracellular cGMP production is achieved by two different forms of guanylyl cyclases: a soluble form (sGC) which is activated by NO; a particulate form (pGC) which is activated by natriuretic peptides, such as ANP, BNP and CNP. cGMP mediates its effects by activating the cGMP-dependent protein kinase (PKG) thus reducing cardiac contractility by inhibition of LTCC activity and reduction of myofilament $\mathrm{Ca}^{2+}$ sensitivity (Méry et al., 1991; Layland et al., 2002; Schroder et al., 2003; Fischmeister et al., 2005).

The intracellular level of these 2 second messengers is regulated by the balance between the activity of $\mathrm{AC} / \mathrm{GC}$ and the cyclic nucleotide phosphodiesterases (PDEs) that degrade cAMP and cGMP to 5'AMP and 5'GMP, respectively. Cardiac PDEs fall into at least five families: PDE1, which is activated by $\mathrm{Ca}^{2+}$-calmodulin; PDE2, which is stimulated by cGMP; PDE3, which is inhibited by cGMP; PDE4 and PDE5. Whereas PDE1 and PDE2 can hydrolyze both cAMP and cGMP, PDE3 preferentially hydrolyzes cAMP; PDE4 and PDE 5 are specific for cAMP and cGMP, respectively.

Although many studies have dissected cAMP and cGMP signaling pathways, there are a number of questions that have always made us wonder but have only lately begun to receive the attention they deserve: how so many different receptors coupled to cAMP or cGMP signaling pathway manage to achieve specific cellular responses? What is the purpose of the different 
adenylyl and guanylyl cyclases present in the same cell? Why do so many different cyclic nucleotide phosphodiesterases (PDEs) coexist to hydrolyze cAMP and cGMP? Do these cyclic nucleotides and their respective effectors freely diffuse inside the cell or are they localized? Some of these questions have received answers in recent studies combining molecular biology, fluorescence imaging, and electrophysiological approaches. In particular, compelling evidence is now accumulating about the formation of molecular complexes (signalosomes) in distinct cellular compartments that induce a localized cyclic nucleotide signaling in cardiomyocyte (Fischmeister et al., 2006).

\section{3- Methods to study cyclic nucleotide compartmentation in intact myocytes}

During twenty years, most of the evidence supporting a compartmentation of cyclic nucleotide signaling in cardiac preparations was gathered using biochemical assays in fractionated dead tissues or cells. However, these methods do not allow understanding the spatiotemporal organization of cyclic nucleotide signals in real time and in living cells. Hence, a number of sophisticated methods have been recently developed to monitor cyclic nucleotide changes using their own targets such as CNG channels (Rich et al., 2000), HCN channels (Nikolaev et al., 2006), PKA (Zaccolo et al., 2000), PKG (Honda et al., 2001), and Epac (Nikolaev et al., 2004) (Fig. 2).

Some of these sensors, such as CNG channels, are based on their ionic channel properties: cAMP and or cGMP levels are measured either by fluorescent calcium probes or by patch clamp technique (Willoughby and Cooper, 2008); whereas, the remaining probes are based on the use of their cAMP and/or cGMP binding domain between YFP and CFP to track cyclic 
nucleotide-dependent changes by FRET (Fluorescence Resonance Energy transfer) between the two fluorescent proteins (fig. 3). Properties of these indicators are summarized in Table 1.

\begin{tabular}{|c|c|c|c|c|}
\hline Probe & PKA & Epac & CNG channels & HCN \\
\hline Methods & FRET imaging & FRET imaging & $\begin{array}{c}\text { Patch Clamp } \\
\text { Calcium imaging }\end{array}$ & FRET imaging \\
\hline Expression & $\begin{array}{l}\text { Microinjection } \\
\text { Plasmid transfection; } \\
\text { adenovirus infection }\end{array}$ & $\begin{array}{l}\text { Plasmid transfection; } \\
\text { adenovirus infection }\end{array}$ & $\begin{array}{l}\text { adenovirus } \\
\text { infection }\end{array}$ & $\begin{array}{c}\text { Transgenic mice } \\
\text { overexpresssing } \\
\text { HNC2-camps }\end{array}$ \\
\hline Dynamic & $\begin{array}{c}\approx 0.02 \mu \mathrm{M}-5 \mu \mathrm{M} \\
\approx 1-100 \mu \mathrm{M}\end{array}$ & $\begin{array}{c}\approx 5-100 \mu \mathrm{M}(\text { Epac : the } \\
\quad \text { whole protein) } \\
\approx 0.1-10 \mu \mathrm{M} \text { (Epac } \\
\text { including cAMP } \\
\quad \text { binding domain) }\end{array}$ & $\begin{array}{c}\approx 1-50 \mu \mathrm{M} \\
(\mathrm{E} 583 \mathrm{M}) \\
\\
\approx 0.1-5 \mu \mathrm{M} \\
(\mathrm{C} 460 \mathrm{~W} / \mathrm{E} 583 \mathrm{M}, \\
\Delta 61- \\
90 / \mathrm{C} 460 \mathrm{~W} / \mathrm{E} 583 \mathrm{M})\end{array}$ & $\begin{array}{c}\approx 5 \mu \mathrm{M} \text { (in vitro) } \\
\text { Excellent } \\
\text { dynamic range }\end{array}$ \\
\hline Localization & $\begin{array}{l}\text { Cytosol, plasmic } \\
\text { membrane, binding } \\
\text { to AKAPs (PKA- } \\
\text { anchoring protein) }\end{array}$ & $\begin{array}{l}\text { Cytosol, plasmic } \\
\text { membrane, } \\
\text { mitochondria, } \\
\text { nucleus }\end{array}$ & $\begin{array}{l}\text { plasmic } \\
\text { membrane }\end{array}$ & $\begin{array}{l}\text { Homogenous } \\
\text { distribution } \\
\text { within the } \\
\text { cytosol }\end{array}$ \\
\hline $\begin{array}{l}\text { Temporal } \\
\text { resolution }\end{array}$ & Limited (many sec) & Good (2 sec) & Excellent $(<15 \mathrm{~ms})$ & Good \\
\hline
\end{tabular}

Table 1: Properties of cAMP sensors. Adapted from (Willoughby \& Cooper, 2008). 


\section{1- Cyclic nucleotide-gated channels: new indicators to track subsarcolemmal cAMP in single living cells}

A novel approach initially developed by the groups of Dermott Cooper and Jeff Karpen uses recombinant $\mathrm{CNG}$ channels as a probe to monitor cyclic nucleotide concentrations generated beneath the membrane (Rich et al., 2001). CNG channels were identified in photoreceptors and olfactory sensory neurons, where they translate changes in intracellular cyclic nucleotide concentration triggered by light or odorants into variations of the membrane potential. Native CNG channels consist of $\alpha$ - and $\beta$-subunits, with the $\alpha$-subunit forming a non-specific cationic pore gated by cAMP or cGMP (Kaupp and Seifert, 2002). Upon binding of the cyclic nucleotide, CNG channels allow $\mathrm{Na}^{+}, \mathrm{K}^{+}$and $\mathrm{Ca}^{2+}$ to enter the cell (Fig. 2) and this activity is easily detected using either patch-clamp or $\mathrm{Ca}^{2+}$-fluorescence measurements (Rich et al., 2000). CNG channels display several characteristics that make them valuable cyclic nucleotide sensors: their gating is fast; they do not desensitize; they are virtually voltage-insensitive; and they display an excellent dynamic range (Rich and Karpen, 2002). The rat olfactory $\alpha$ subunit (CNGA2) makes a valuable cGMP sensor that was used recently to show cGMP compartmentation in cardiac myocytes (Castro et al., 2006; Castro et al., 2010). In order to study selectively cAMP dynamics, Rich et al. (Rich et al., 2001) have made point mutations in CNGA2 to decrease the sensitivity to cGMP and increase the sensitivity to cAMP. In particular, the $\mathrm{E} 583 \mathrm{M}$ mutation confers on the channel an $\mathrm{EC}_{50}$ for cAMP of approximately $10 \mu \mathrm{M}$, and the additional C460W mutation further increases the sensitivity, to approximately $1 \mu \mathrm{M}$. These CNGA2 mutants were incorporated into adenovirus constructs to allow efficient expression in various cell types (Vandecasteele et al., 2006). Adult cardiac myocytes infected with an adenovirus encoding the modified channels elicit a non-selective cation current that provides a 
reliable readout of subsarcolemmal cAMP fluctuations (Rochais et al., 2004; Rochais et al., 2006; Leroy et al., 2008; Abi-Gerges et al., 2009).

Because CNG channels are blocked by external and internal $\mathrm{Ca}^{2+}$ as well as by calmodulin $(\mathrm{CaM})$, patch clamp experiments should be performed at nominal external $\left[\mathrm{Ca}^{2+}\right]$ and internal pCa 8.5 (Rochais et al., 2004; Castro et al., 2006). Since $\mathrm{Ca}^{2+}$ regulates the activity of cardiac AC and PDEs, thus modulating cAMP signals, other CNG mutants $((\Delta 61-$ 90/C460W/E583M or F68A/W81A/C460/E583M) that do not bind to $\mathrm{Ca}^{2+} / \mathrm{CaM}$ complex have been generated later on (Rich et al., 2001; Willoughby and Cooper, 2007; Dubois, 1985).

The use of CNG channels in HEK cells showed that the activation of prostaglandin E1 (PGE1) receptors generates 2 types of cAMP signals: a rapid and transient increase of cAMP beneath the membrane while the increase in total cytosolic cAMP level is slow and sustained. The transient increase of submembrane cAMP was abolished after PDE inhibition (Rich et al., 2001).

In a series of studies performed in isolated rat cardiac myocytes, the use of CNG mutants showed the first evidence in real time that subsarcolemmal cAMP signals generated upon activation of different GPCRs are spatially confined in specific microdomains and are highly controlled by a specific pattern of PDEs (Rochais et al., 2004; Rochais et al., 2006). Besides, cAMP levels elicited upon a $\beta$-adrenergic stimulation were shown to be negatively tuned by PKA-mediated activation of PDE3/PDE4 (Rochais et al., 2004). Leroy and colleagues combined the use of the CNG channels with the FRET-based sensor, Epac2-camps in order to monitor respectively cAMP signals generated beneath the membrane and in the cytosol (Leroy et al., 2008). 
Biochemical assays showed that the cAMP pathway is altered during cardiac hypertrophy and heart failure. Using the engineered CNG channels, we provided the first evidence, in real time and on living, hypertrophied cardiac myocytes, that subsarcolemmal cAMP signals generated upon the activation of $\beta$-adrenergic receptors are blunted compared to normal cardiac myocytes. The regulation of these cAMP domains by PDEs is also altered during hypertrophy (Abi-Gerges et al., 2009).

\section{2- Hyperpolarization-activated, cyclic nucleotide-gated channels: a novel sensor to monitor cytosolic cAMP in living cells}

Hyperpolarization-activated, cyclic nucleotide-gated cation channels (HCN) are voltagedependent channels activated by hyperpolarization and sensitive to the cyclic nucleotides, cAMP and cGMP. They are permeable to the monovalent cations $\mathrm{K}^{+}$and $\mathrm{Na}^{+}$. In vertebrate, $\mathrm{HCN}$ family comprises 4 members (HCN1-4). While $\mathrm{HCN} 3$ is specifically expressed in neurons, the 3 other channels (HCN 1, 2 and 4) are detected in heart and brain. The HCN4 isoform is mainly expressed in sino-atrial cells while $\mathrm{HCN} 2$ is dominant in atrial and ventricular myocytes. $\mathrm{HCN}$ channels have, in their C-terminal part, a cyclic-nucleotide binding domain which is similar to the one that is present in PKA, PKG, Epac and CNG channels. The current associated to these channels is known as the 'funny' current $\left(\mathrm{I}_{\mathrm{f}}\right)$ or the pacemaker current. It contributes to the generation of the cardiac automatism in the cells of the sino-atrial and atrio-ventricular node (Biel et al., 2002; Mangoni and Nargeot, 2008).

cAMP probes based on the use of PKA and Epac have the inherent disadvantage that their sensitivity is relatively high (affinity for cAMP $\approx 1 \mu \mathrm{M}$ ). Therefore, the determination of cAMP with these constructs is limited to the low range of cAMP concentrations, which is 
inadapted to cells in which cAMP can reach micromolar concentrations, such as cardiac myocytes. Therefore, Nikolaev and colleagues have developed a novel sensor with optimized sensitivity to cAMP based on the use of a single cytoplasmic cAMP binding domain of HCN2 channel endogenously expressed in the heart, known as HCN2-camps (Nikolaev et al., 2006). Based on the crystal structure of $\mathrm{HCN}$, they fused its cAMP binding domain between YFP and CFP to monitor cAMP-dependent conformational changes by FRET between the 2 fluorescent proteins (Fig. 3). This sensor, isolated from HEK293 cells, demonstrated micromolar affinities for cAMP whereas cGMP activated the sensor only partially at high micromolar concentrations. HCN2-camps sensor was expressed in a cardiomyocyte-specific manner in the hearts of transgenic mice in order to study spatial and temporal cAMP dynamics after $\beta_{1^{-}}$and $\beta_{2^{-}}$ adrenergic subtype stimulation in freshly isolated adult cardiac myocytes. Using this probe that is uniformly expressed in the cell, the authors showed that a localized $\beta_{1}$-adrenergic stimulation generated a cAMP gradient propagating throughout the cell, whereas local $\beta_{2}$-adrenergic stimulation elicited confined cAMP pools. Besides, the activation of $\beta_{1}$-adrenergic receptors elicited cAMP signals that were entirely controlled by PDE4, whereas the activation of $\beta_{2}$ adrenergic receptors generated cAMP signals regulated by multiple PDE isoforms. Even after PDE inhibition, the $\beta_{2}$-adrenergic-mediated cAMP signals were still confined within the cells suggesting a role of the cell architecture in cAMP compartmentation (Nikolaev et al., 2006).

\section{4- Conclusion}

A number of different probes are now available for real time measurements of cAMP(Nikolaev et al., 2004; Zaccolo, 2004; Nikolaev et al., 2005) and cGMP in living cells, 
including cardiac myocytes. The first approach is based on the properties of CNG channels that are directly activated by the increase of cAMP and cGMP concentrations beneath the membrane. In order, to visualize changes in cyclic nucleotide levels within the cytosol, another type of approach based on FRET imaging has been developed using cAMP and cGMP targets. Combining the two techniques allows a better understanding of the spatiotemporal organization of cyclic nucleotide signaling in many cell types.

\section{Summary}

Signaling cascades involving cyclic nucleotides play key roles in signal transduction in virtually all cell types. A current challenge in research today is to decipher the spatiotemporal regulation of cyclic nucleotide signaling that any given cell type has concocted to be able to discriminate among different external stimuli acting via a common signaling pathway. New approaches based on the use of ion channels as biosensors have been recently developed in order to track the dynamics of cAMP and cGMP as well as the activities of their regulators and effectors in the native biological context. This obviously applies to cyclic nucleotide gated channels (CNG) (Fagan et al., 2001; Rich et al., 2001; Rich et al., 2001; Brady et al., 2004) and the hyperpolarization-activated cyclic nucleotide-gated channels (HCN) (Nikolaev et al., 2006) whose high sensitivity to cAMP and/or cGMP allow to monitor in real time and in living cells the signals encoded by these second messengers (Rochais et al., 2004; Rochais et al., 2006; Castro et al., 2006; Leroy et al., 2008; Castro et al., 2010; Abi-Gerges et al., 2009). Here we review a series of genetically encoded probes based on the use of CNG and HCN channels for real-time monitoring of cyclic nucleotide signaling with a particular focus on their implementation in cardiac myocytes. 


\section{Cross-References}

$\rightarrow$ Cyclic nucleotide gated channels: HCN and CNG Long Entry 00652 110/110

$\rightarrow$ Cys loop ligand gated channels and ionotropic glutamate receptors Long Entry $00361112 / 112$

$\rightarrow$ Fluorescence and FRET Long Entry 00559 187/187

$\rightarrow$ Fluoresence based techniques for studying ion channel gating - voltage clamp fluorometry, LRET, FRET Long Entry 00375 196/196

$\rightarrow$ Gating of potassium channels by cyclic nucleotide binding Medium Entry 00473 208/208

$\rightarrow$ Introduction to studies of macromolecular interactions Long Entry 00304 253/253

$\rightarrow$ Ion channel regulation by G-protein coupled receptors - recent advances with optical biosensors Long Entry 00384 255/255

$\rightarrow$ KATP and the sulphonylurea receptor Long Entry $00582266 / 266$

$\rightarrow$ Live cell imaging Medium Entry 00513 292/292

$\rightarrow$ Modelling the heart Long Entry 00379 328/328

$\rightarrow$ Molecular dynamics Medium Entry 00093 330/330

$\rightarrow$ Nitric oxide synthase Medium Entry $00000_{361 / 361}$

$\rightarrow$ Phosphorylation Medium Entry $00184396 / 396$

$\rightarrow$ Predicting the structure of protein complexes Long Entry $00000_{416 / 416}$

$\rightarrow$ Protein-Protein Complexes Long Entry $00212_{433 / 433}$

$\rightarrow$ Relatives of the voltage gated family: HCN; CNG; TRP; CatSper Long Entry 00359 459/459

\section{References}

Abi-Gerges A, Richter W, Lefebvre F, Matéo P, Varin A, Heymes C, Samuel J-L, Lugnier C, Conti M, Fischmeister R, Vandecasteele G (2009) Decreased expression and activity of cAMP phosphodiesterases in cardiac hypertrophy and its impact on $B$-adrenergic cAMP signals. Circ Res 105:784-792.

Baruscotti M, Bucchi A, DiFrancesco D (2005) Physiology and pharmacology of the cardiac pacemaker ("funny") current. Pharmacol Ther 107:59-79. 
Bers DM (2002) Cardiac excitation-contraction coupling. Nature 415:198-205.

Biel M, Schneider A, Wahl C (2002) Cardiac HCN channels: structure, function, and modulation. Trends Cardiovasc Med 12:206-212.

Bos JL (2003) Epac: a new cAMP target and new avenues in cAMP research. Nat Rev Mol Cell Biol 4:733-738.

Brady JD, Rich TC, Le X, Stafford K, Fowler CJ, Lynch L, Karpen JW, Brown RL, Martens JR (2004) Functional role of lipid raft microdomains in cyclic nucleotide-gated channel activation. Mol Pharmacol 65:503-511.

Castro LRV, Schittl J, Fischmeister R (2010) Feedback control through cGMP-dependent protein kinase contributes to differential regulation and compartmentation of cGMP in rat cardiac myocytes. Circulation Research 107:1232-1240.

Castro LRV, Verde I, Cooper DMF, Fischmeister R (2006) Cyclic guanosine monophosphate compartmentation in rat cardiac myocytes. Circulation 113:2221-2228.

Dhein S, Van Koppen CJ, Brodde OE (2001) Muscarinic receptors in the mammalian heart. Pharmacol Res 44:161-182.

Dubois J-M (1985) Physiologie et pharmacologie des canaux Na et K des membranes axonales. J Physiol (Paris) 80: 120-128.

Fagan KA, Schaack J, Zweifach A, Cooper DMF (2001) Adenovirus encoded cyclic nucleotidegated channels: a new methodology for monitoring cAMP in living cells. FEBS Lett 500:85-90.

Fischmeister R, Castro L, Abi-Gerges A, Rochais F, Vandecasteele G (2005) Species- and tissue-dependent effects of NO and cyclic GMP on cardiac ion channels. Comp Biochem Physiol A Mol Integr Physiol 142:136-143.

Fischmeister R, Castro LRV, Abi-Gerges A, Rochais F, Jurevičius J, Leroy J, Vandecasteele G (2006) Compartmentation of cyclic nucleotide signaling in the heart: The role of cyclic nucleotide phosphodiesterases. Circ Res 99:816-828.

Honda A, Adams SR, Sawyer CL, Lev-Ram V, Tsien RY, Dostmann WR (2001) Spatiotemporal dynamics of guanosine 3',5'-cyclic monophosphate revealed by a genetically encoded, fluorescent indicator. Proc Natl Acad Sci USA 98:2437-2442.

Kaupp UB, Seifert R (2002) Cyclic nucleotide-gated ion channels. Physiol Rev 82:769-824.

Layland J, Li JM, Shah AM (2002) Role of cyclic GMP-denendent protein kinase in the contractile response to exogenous nitric oxide in rat cardiac myocytes. J Physiol 540:457-467. 
Leroy J, Abi-Gerges A, Nikolaev VO, Richter W, Lechęne P, Mazet J-L, Conti M, Fischmeister R, Vandecasteele G (2008) Spatiotemporal dynamics of $\beta$-adrenergic cAMP signals and L-type $\mathrm{Ca}^{2+}$ channel regulation in adult rat ventricular myocytes: Role of phosphodiesterases. Circ Res 102:1091-1100.

Mangoni ME, Nargeot J (2008) Genesis and regulation of the heart automaticity. Physiol Rev 88:919-982.

Morel E, Marcantoni A, Gastineau M, Birkedal R, Rochais F, Garnier A, Lompré A-M, Vandecasteele G, Lezoualc'h F (2005) The cAMP-binding protein Epac induces cardiomyocyte hypertrophy. Circ Res 97:1296-1304.

Méry P-F, Lohmann SM, Walter U, Fischmeister R (1991) $\mathrm{Ca}^{2+}$ current is regulated by cyclic GMP-dependent protein kinase in mammalian cardiac myocytes. Proc Natl Acad Sci USA 88:1197-1201.

Nikolaev VO, Bunemann M, Hein L, Hannawacker A, Lohse MJ (2004) Novel single chain cAMP sensors for receptor-induced signal propagation. J Biol Chem 279:37215-37218.

Nikolaev VO, Bunemann M, Schmitteckert E, Lohse MJ, Engelhardt S (2006) Cyclic AMP imaging in adult cardiac myocytes reveals far-reaching $\beta_{1}$-adrenergic but locally confined $\beta_{2}$ adrenergic receptor-mediated signaling. Circ Res 99:1084-1091.

Nikolaev VO, Gambaryan S, Engelhardt S, Walter U, Lohse MJ (2005) Real-time monitoring of live cell's PDE2 activity: Hormone-stimulated cAMP hydrolysis is faster than hormonestimulated cAMP synthesis. J Biol Chem 280:1716-1719.

Ponsioen B, Zhao J, Riedl J, Zwartkruis F, van der Krogt G, Zaccolo M, Moolenaar WH, Bos JL, Jalink K (2004) Detecting cAMP-induced Epac activation by fluorescence resonance energy transfer: Epac as a novel cAMP indicator. EMBO Rep 5:1176-1180.

Rich TC, Fagan KA, Nakata H, Schaack J, Cooper DMF, Karpen JW (2000) Cyclic nucleotidegated channels colocalize with adenylyl cyclase in regions of restricted cAMP diffusion. J Gen Physiol 116:147-161.

Rich TC, Fagan KA, Tse TE, Schaack J, Cooper DM, Karpen JW (2001) A uniform extracellular stimulus triggers distinct cAMP signals in different compartments of a simple cell. Proc Natl Acad Sci USA 98:13049-13054.

Rich TC, Karpen JW (2002) Review article: cyclic AMP sensors in living cells: what signals can they actually measure? Ann Biomed Eng 30:1088-1099.

Rich TC, Tse TE, Rohan JG, Schaack J, Karpen JW (2001) In vivo assessment of local 
phosphodiesterase activity using tailored cyclic nucleotide-gated channels as cAMP sensors. $\mathbf{J}$ Gen Physiol 118:63-77.

Rochais F, Abi-Gerges A, Horner K, Lefebvre F, Cooper DMF, Conti M, Fischmeister R, Vandecasteele G (2006) A specific pattern of phosphodiesterases controls the cAMP signals generated by different $\mathrm{G}_{\mathrm{s}}$-coupled receptors in adult rat ventricular myocytes. Circ Res 98:10811088 .

Rochais F, Vandecasteele G, Lefebvre F, Lugnier C, Lum H, Mazet J-L, Cooper DMF, Fischmeister R ( 2004) Negative feedback exerted by PKA and cAMP phosphodiesterase on subsarcolemmal cAMP signals in intact cardiac myocytes. An in vivo study using adenovirusmediated expression of CNG channels. J Biol Chem 279:52095-52105.

Schroder F, Klein G, Fiedler B, Bastein M, Schnasse N, Hillmer A, Ames S, Gambaryan S , Drexler H, Walter U, Lohmann SM, Wollert KC (2003) Single L-type $\mathrm{Ca}^{2+}$ channel regulation by cGMP-dependent protein kinase type I in adult cardiomyocytes from PKG I transgenic mice. Cardiovasc Res 60:268-277.

Vandecasteele G, Rochais F, Abi-Gerges A, Fischmeister R (2006) Functional localization of cAMP signalling in cardiac myocytes. Biochem Soc Trans 34:484-488.

Willoughby D, Cooper DM (2007) Organization and $\mathrm{Ca}^{2+}$ regulation of adenylyl cyclases in cAMP microdomains. Physiol Rev 87:965-1010.

Willoughby D, Cooper DM (2008) Live-cell imaging of cAMP dynamics. Nat Methods 5:29-36.

Zaccolo M (2004) Use of chimeric fluorescent proteins and fluorescence resonance energy transfer to monitor cellular responses. Circ Res 94:866-873.

Zaccolo M, De Giorgi F, Cho CY, Feng L, Knapp T, Negulescu PA, Taylor SS, Tsien RY, Pozzan T (2000) A genetically encoded, fluorescent indicator for cyclic AMP in living cells. Nat Cell Biol 2:25-29.

\section{Keywords}

Ion channels, biosensors, cAMP, cGMP, signaling, CNG, $\mathrm{HCN}$ 


\section{Figure Legends}

\section{Figure 1: Regulation of cardiac excitation-contraction coupling by cAMP pathways}

Upon liberation of noradrenaline by sympathetic nerve terminals, $\beta 1$-ARs activate cardiac AC isoforms (AC5 and AC6) via the stimulatory G protein (Gs). Cyclic AMP is being synthesized and activates PKA which phosphorylates different intracellular targets: LTCC phosphorylation leads to an increased $\mathrm{Ca} 2+$ influx and RyR2 phosphorylation at the SR membrane to an increased $\mathrm{Ca} 2+$-induced $\mathrm{Ca} 2+$ release, both acting to enhance the force of contraction; PLB phosphorylation leads to an increased SR Ca2+ uptake by SERCA and TnI phosphorylation to a reduction in $\mathrm{Ca} 2+$-sensitivity of the myofilaments, both acting to accelerate contractile relaxation; on the long term, CREB phosphorylation in the nucleus activates transcription. These effects are antagonized by a liberation of acetylcholine from parasympathetic nerve terminals, through activation of muscarinic $\mathrm{M} 2$ receptors and inhibition of AC activity via inhibitory $\mathrm{G}$ proteins $(\mathrm{Gi})$.

Figure 2: CNG channels as cyclic nucleotide biosensors

(A) Expression of CNGA2 as revealed by confocal microscopy in native and Ad-CNG (adenovirus carrying CNG)-infected adult rat ventricular myocytes cultured for $24 \mathrm{~h}$. CNGA2 mutant was detected using a mouse monoclonal anti-CNGA2 kindly provided by Dr F. Muller and Professor U.B. Kaupp (Institute for Biological Information Processing, Research Centre Julich, Julich, Germany). No CNG channels were detected in non-infected (NI) cells, whereas Ad-CNG-infected cells demonstrated a rather ubiquitous pattern of expression with accentuation of the staining at the Z-lines. (B) Recombinant CNG channels. Wild-type or genetically modified $\alpha$ subunits of rat olfactory $\mathrm{CNG}$ channel (CNGA2) form a cationic channel directly opened by cyclic nucleotides $(\mathrm{CN})$. (C) Cardiomyocytes infected with an adenovirus encoding the native or modified channels elicit a non-selective cation current $\left(\mathrm{I}_{\mathrm{CNG}}\right)$ only when $\mathrm{CN}$ concentration rises beneath the sarcolemmal membrane.

\section{Figure 3: HCN channels as CAMP biosensors}

(A) FRET-based imaging method. YFP and CFP proteins are fused to a cyclic nucleotide (CN) binding protein (for instance, $\mathrm{HCN}$, Epac or a catalytic-inactive $\mathrm{PKG}$ ). $\mathrm{CN}$ binding reduces 
FRET between CFP and YFP and the change in shape of the fluorescence emission spectrum allows $\mathrm{CN}$ concentrations to be visualized in real-time. (B) $\mathrm{CN}$ imaging in a living cell (rat ventricular myocyte). CFP/YFP ratio is expressed in color code and is proportional to $\mathrm{CN}$ concentration within the cell. 


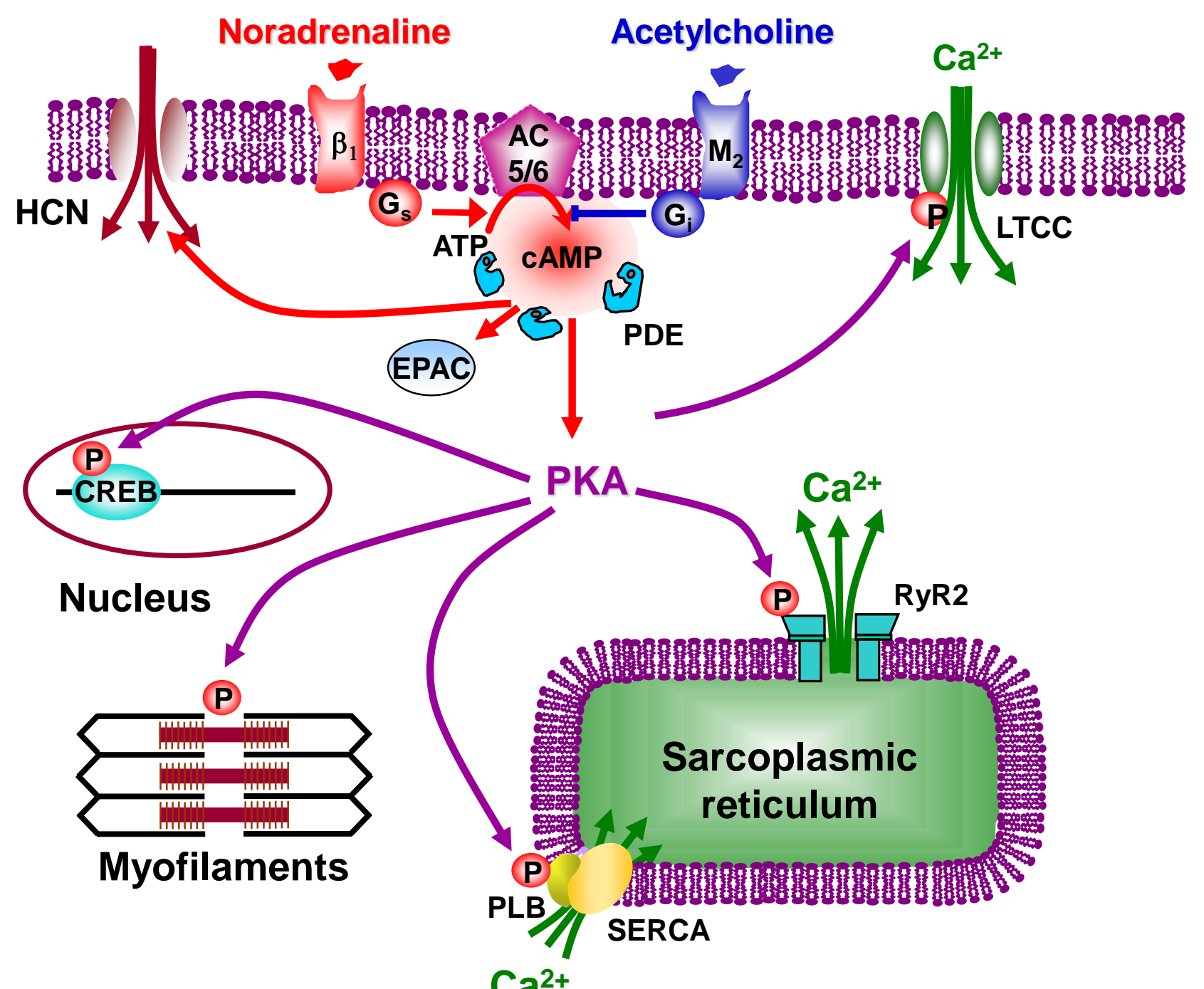

Figure 1 
A

Non infected

Ad-CNG
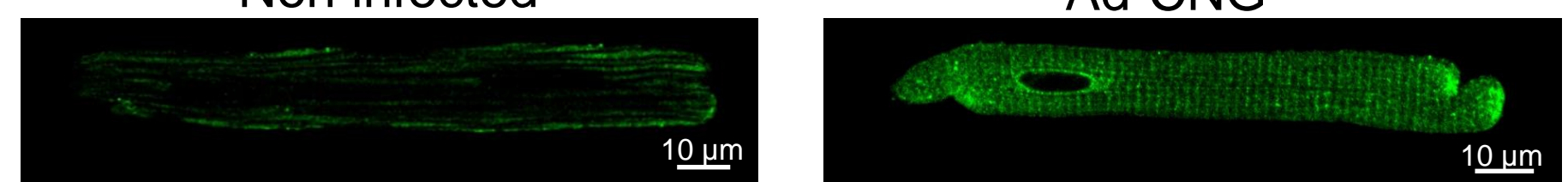

B

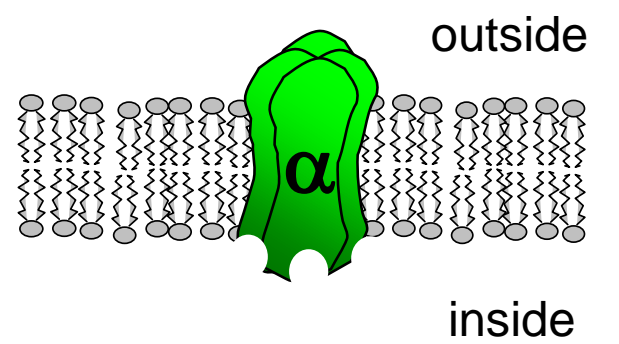

sarcolemma

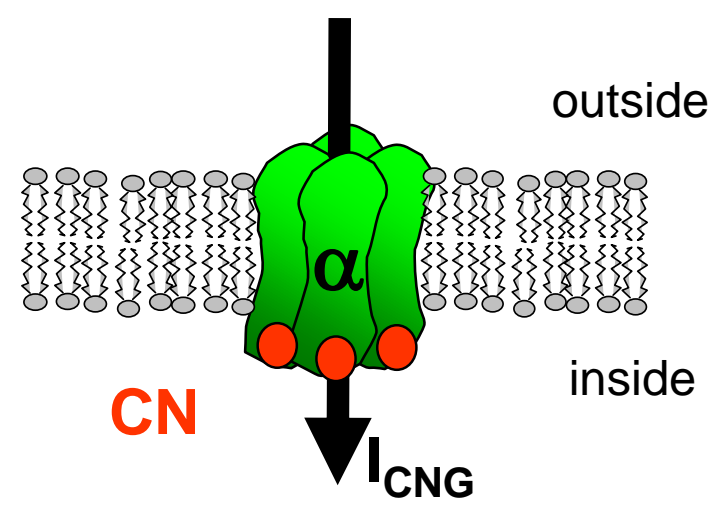

C
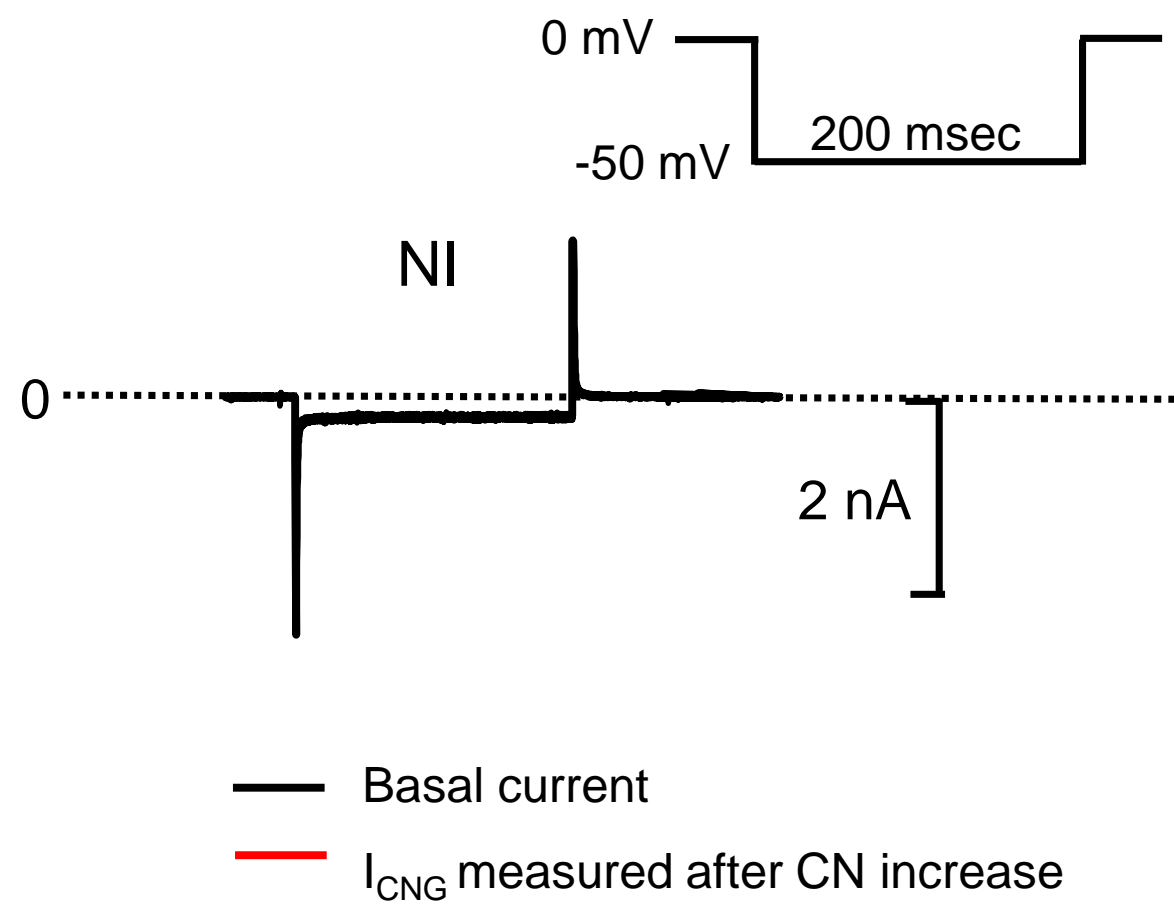

Ad-CNG

Figure 2 
A

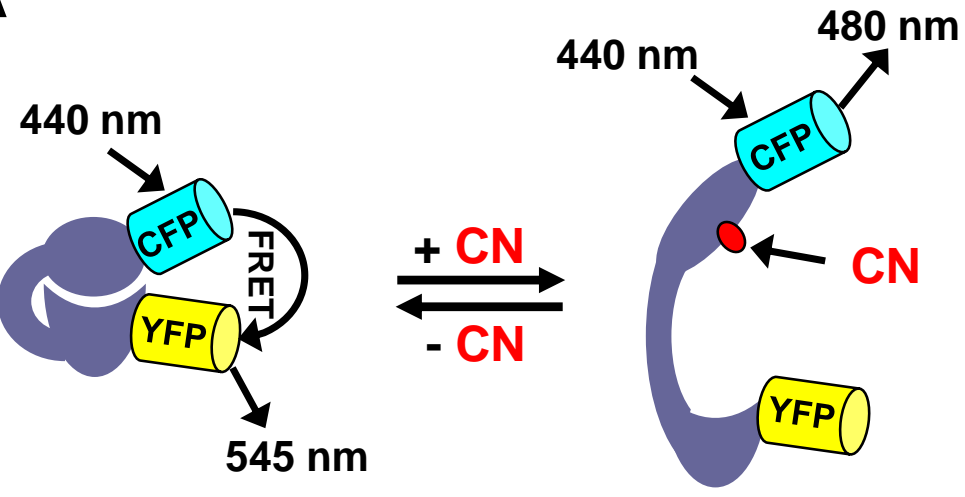

B

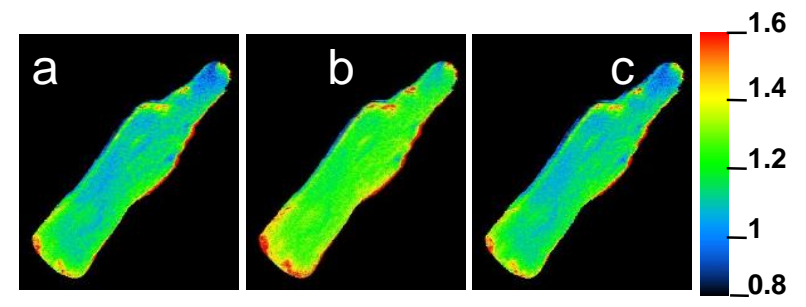

Figure 3 